\title{
Effectiveness of Structured Teaching Programme On Knowledge, Attitude And Practice Of High Risk People On Prevention Of Oral Cancer
}

Mrs. Bamalakshmi. V

\section{Abstract:}

Background: Cancer is a uncontrollable growth of cells that invade and cause damage to surrounding tissues. Worldwide, oral cancer is the sixth most common cancer, representing about 5.5\% of all malignancies and approximately 2\% of all cancer death. Objectives: To assess the knowledge, attitude and practice of high risk people on prevention of oral cancer, To determine the effectiveness of structured teaching programme on knowledge, attitude and practice of high risk people on prevention of oral cancer, To associate the selected demographic variables with knowledge, attitude and practice of high risk people on prevention of oral cancer, To correlate the knowledge, attitude and practice of high risk people on prevention of oral cancer. Methods: Quasi experimental research design (one group pre-test and post-test). 50 samples were selected through purposive sampling technique who met the inclusion criteria. After pre-test structured teaching programme on Prevention of Oral Cancer was provided through lecture cum discussion.Results: Findings revealed that in pre-test majority 48 (78.3\%) of the high risk people had inadequate knowledge and most of them were 10(16.7\%) had unfavorable attitude, whereas in the post-test $36(60 \%)$ of them had moderately adequate knowledge and none of them had neutral attitude. There is significant difference $(p<0.001)$ found in knowledge attitude and practice of high risk people after the structured teaching programme. Conclusion: The findings of this study showed that the structured teaching programme is statistically effective in improving knowledge attitude and practice of high risk people on prevention of oral cancer .This study will help to motivate the high risk people in society to prevent themselves and others from oral cancer.

Keyword: High Risk People \&Prevention Of Oral Cancer

\section{INTRODUCTION}

World Health Organization defines health is a state of complete physical mental and social wellbeing and not merely an absence of disease or infirmity. An unhealthy lifestyle and
Practices among an individual will lead to a disease. Cancer is an abnormal disorganized growth of cells in the tissue of a person.

Cancer cells keep on multiplying without paying head to the body's command to stop ${ }^{1}$. Cancer of the oral cavity which may 
occurs in any part of the mouth or throat. Despite of several measures of public awareness still the common man is unaware of its complications and economic burden leading to individual and health care system of country?

\section{Need for the study}

Oral cancer is the sixth most common cancer reported globally with an annual incidence of over 300,000 cases, of which $62 \%$ arise in developing countries. Cancer is one of the most common causes of morbidity and mortality today, with more than 10 million new cases \& more than 6 million deaths each year worldwide ${ }^{3}$. Tobacco use and alcohol are known risk factors for cancers of the oral cavity. Besides smoking, use of smokeless tobacco is widely prevalen ${ }^{4}$. The use of Betel quid like pan is very common and is accepted socially and culturally in many parts of India. Additionally, gutka, zarda, kharra, mawa and khainni are all dry mixtures of lime, areca nut flakes and powdered tobacco custom mixed by vendors. Various studies carried out across the country report that at least one third of school students less than 15 years of age have used one form or another of tobacco. However, with improved public health education, the prevalence of these risk factors is decreasing around the globe, including in India 5 .

\section{Objectives}

- To assess the knowledge, attitude and practice of high risk peoples regarding prevention of oral cancer.

- To determine the effectiveness of structured teaching programme on knowledge, attitude and practice of high risk peoples regarding prevention of oral cancer.

- To associate the selected demographic variables with knowledge, attitude and practice of high risk peoples regarding prevention of oral cancer.

\section{Hypothesis}

- H1- There is a difference in knowledge, attitude and practice of high risk people on prevention of oral cancer before and after structured teaching programme.

- H2- There is association between selected variables and knowledge, attitude and practice of high risk people on prevention of oral cancer.

\section{Methodology:}

The research design used for this study was pre-experimental research design (one group pre-test and post-test). 50 samples were selected through purposive sampling technique who met the inclusion criteria. After pre-test structured teaching programme on Prevention of Oral Cancer was provided through lecture cum discussion. Flash card was used as audio-visual aids. Post-test was conducted after the gap of 7 days of Structured Teaching Programme. The data were analysed by using descriptive and inferential statistics like frequency, percentage, mean, standard deviation, paired T-Test and Chi-Square test.

\section{Major Findings:}

The investigator found that, among the subjects $54(90 \%)$ were in the age group of high risk people. Half of them were studying in III year 56(93\%) and 59(98.3\%) were unmarried. Majority of the subjects 54(90\%) were from nuclear family. Majority of the subjects $47(81.6 \%)$ were from Hindu religion. Most of them were living in rural area 30 (50\%). 46(76.7\%) of subjects did not have previous exposure to knowledge on Prevention of Oral cancer and only 14 (23.3\%) had previous exposure on Prevention of Oral Cancer through Mass Media, Internet, Television and Health Personal. In pre-test majority 48 (78.3\%) of the high risk people had inadequate knowledge and most of them were $10(16.7 \%)$ had unfavorable attitude, whereas in the 
post-test $36(60 \%)$ of them had moderately adequate knowledge and none of them had neutral attitude. There is significant difference $(\mathrm{P}<0.001)$ found in knowledge attitude and practice of high risk people after the structured teaching programme. There is no significant association found at $5 \%(\mathrm{P}<0.005)$ between knowledge attitude and Practice of a high risk people on prevention with selected demographic variable

Table: 1 Determine the effectiveness of structured teaching programme on knowledge of high risk people on prevention of oral cancer.

$(\mathrm{N}=\mathbf{5 0})$

\begin{tabular}{|l|l|l|l|l|l|}
\hline Attitude & Mean & Median & $\begin{array}{l}\text { Standard } \\
\text { Deviation }\end{array}$ & $\begin{array}{l}\text { Wilcoxon } \\
\text { Test }\end{array}$ & p-value \\
\hline Pretest & -3.86 & -4 & 4.61 & -6.097 & $<0.001^{*}$ \\
\hline Postest & 8.28 & 8 & 1.95 & \\
\hline
\end{tabular}

Table: 3shows that the post-test level of practice (8) among the high risk people on prevention of oral cancer was significant high $(\mathrm{p}<0.001)$ when compared to pretest level by Wilcoxon signed rank test. It indicates that the structured teaching programme was effective to high risk people on prevention of oral cancer.

\section{Summary and Conclusion:}

This chapter gives a brief an account of the outcome of the study conducted in Adingapattu, Puducherry. The research design used for this study quasi-experimental (one group pre-test and post-test).50 samples were selected through purposive sampling technique. The high risk people assessed pre-test for the knowledge, attitude and practice on prevention of oral cancer with the use of structure interview questionnaire and structured and self-administered questionnaire respectively. After pre-test structure teaching program on prevention of oral cancer was provided through lecture cum discussion. Flash card was used as audio visual aids. Post-test was conducted after the gap of 7 days of structure teaching program.
The data was analyzed by using descriptive and inferential statistics like frequency, percentage, mean, standard deviation, Wilcoxon signed ranks test, Kruskal-Wallis test, Mann Whitney test, chi-square test. The findings of this study showed that the structured teaching programme is statistically effective in improving knowledge attitude and practice of high risk people regarding prevention of oral cancer .This study will help the prevention of

oral cancer to teach and motivate the high risk peoples in society to prevent themselves and others from oral cancer.

\section{Recommendations:}

- A descriptive study can be conducted to assess the knowledge, attitude and practice among the family members and physician other than the high risk people.

- A comparative study can be conducted to assess the effectiveness of structured teaching programme on high risk people among the family members and physician using large number of samples. 


\section{References}

- 1. Lewis "A textbook of medical \& surgical nursing" published by Mosby in the year, 2004, page no 1008 to 1009.

- 2. M.C. Gupta "A textbook of preventive \& social medicine" $3^{\text {rd }}$ edition published by Jaypee Brothers in the year 2003, page no 624 to 625 .

- 3. American Cancer Society. Cancer Facts and Figures 2013. Atlanta: American Society; 2013 page no 15-7.

- 4. IARC Science Publ. "An intervention study of tobacco chewing and smoking habits for primary prevention of oral cancer in India", in 1986, P.No. 307-318.

- 5. Cancer Research Clinic Oncology "Chewing and smoking habits in relation to pre cancer and oral cancer", in 1981, P.No. 35-39.

\section{HYPOCALCEMIA SYMPTOMS}

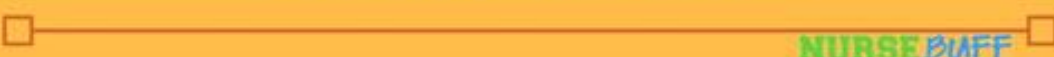

Convulsions

Arrhythmias

Tetany

pasms and stridor

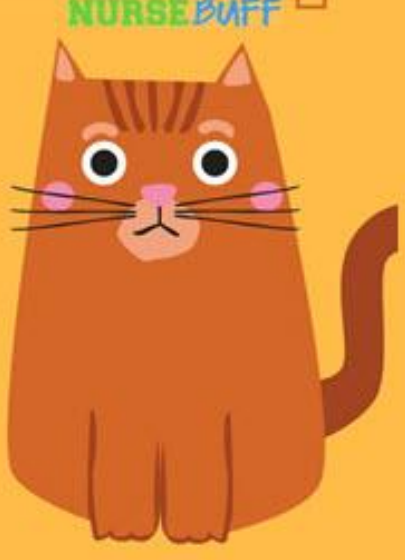

